\title{
Staged percutaneous angioplasty of a long calcified left anterior descending artery with rotablation in a patient with stable angina
}

\author{
Jakub Podolec, Piotr Szolc, Monika Durak, Wojciech Zajdel, Łukasz Niewiara, Krzysztof Żmudka \\ Department of Interventional Cardiology, Jagiellonian University Medical College, John Paul II Hospital, Krakow, Poland
}

Adv Interv Cardiol 2018; 14, 2 (52): 206-207

DOI: https://doi.org/10.5114/aic.2018.76417

A 68-year-old female patient was admitted to the Department of Interventional Cardiology for the next stage of percutaneous coronary intervention $(\mathrm{PCl})$ of a long, heavy calcified lesion in the left anterior descending (LAD) artery. The patient was treated for arterial hypertension, dyslipidemia and diabetes mellitus type 2 . One month prior to admission, the patient underwent $\mathrm{PCl}$ of the circumflex artery. The patient still reported symptoms of stable angina (class II according the CCS classification).

The procedure was performed using right radial artery access. Distal parts of the LAD and diagonal branch (Dg2) were secured using Sion Blue guidewires. All of the compliant and non-compliant (NC) balloons starting from 2.0/20 mm, NC Emerge 2.5/15 mm and NC Emerge 3.0/15 $\mathrm{mm}$ with pressures up to $26 \mathrm{~atm}$ were used for pre-dilatation and crushed during the inflation. A strongly calcified, critical narrowing in the LAD was still present. The first attempt at delivering the Flextome Cutting Balloon 2.5/15 mm using the buddy-wire technique was unsuccessful. Introduction of the GuideLiner catheter facilitated inflation of the Flextome Cutting Balloon 2.5/15 $\mathrm{mm}$. Due to the persistent, calcified narrowing with no improvement, the operator decided to perform the rotablation procedure. The RotaWire was introduced to the distal part of the LAD and 4 passages of Burr 1.5 $160000 \mathrm{rpm}$ (8 s in duration each) were performed. The next inflations of the Flextome Cutting Balloon with pressures of 6-12 atm and NC Emerge $3.0 / 8 \mathrm{~mm}$ with pressures of 18-24 atm were made. The effect was suboptimal with residual stenosis of $70 \%$. Due to the large dose of contrast infusion, prolonged radiation time, and clinically and angiographically stable condition of the patient, the procedure was terminated.
Five days later, the next attempt via right femoral access with a $7 \mathrm{Fr}$ catheter was performed. The distal part of the LAD was secured using Extra Support RotaWire. Three passages with Burr 1.75 mm 160000 rpm and another 3 passages of Burr $2.0 \mathrm{~mm} 160000 \mathrm{rpm}$ ( $8 \mathrm{~s}$ in duration) were needed. Inflation of the NC balloon 3.0/15 $\mathrm{mm}$ with a pressure up to $20 \mathrm{~atm}$ was made, finally achieving successful pre-dilatation of the LAD. Angiography revealed linear dissection in the mid LAD. The first attempt at stent delivery was unsuccessful but the use of the GuideLiner catheter facilitated implantation of the Orsiro 3.0/40 mm stent in the mid LAD (10 atm). The dissection was fully covered. Next, the Xience $3.5 / 18 \mathrm{~mm}$ stent was implanted in the proximal LAD with a pressure of $10 \mathrm{~atm}$. Post-dilatation over the whole length of the stent was done using a $3.5 / 18 \mathrm{~mm}$ balloon with pressure up to $18 \mathrm{~atm}$. The final result of the angioplasty was optimal with TIMI 3 flow and no residual stenosis (Figure 1). Two days later, the patient was discharged from the hospital.

Percutaneous treatment of long, highly calcified lesions in the coronary arteries can be challenging. It is crucial to optimally prepare the lesion prior to stent implantation. The Rotablation technique, as well as use of the GuideLiner catheter, is often necessary to achieve an optimal result [1-3]. Prolonged contrast injection and radiation exposure time should be monitored and the procedure should be staged, if necessary, to decrease the risk of contrast-induced nephropathy. The incidence of complications during rotablation has dropped over the last 3 years and the method should be more often considered in treatment of calcified lesions [4]. Careful rotablation with a larger burr is of great advantage to create a sufficient lumen size before stent implantation.

\section{Corresponding author:}

Jakub Podolec, Department of Interventional Cardiology, John Paul II Hospital, Jagiellonian University Medical College, 80 Prądnicka St, 31-202 Krakow, Poland, e-mail: jjpodolec@gmail.com

Received: 27.02.2018, accepted: 21.03.2018. 

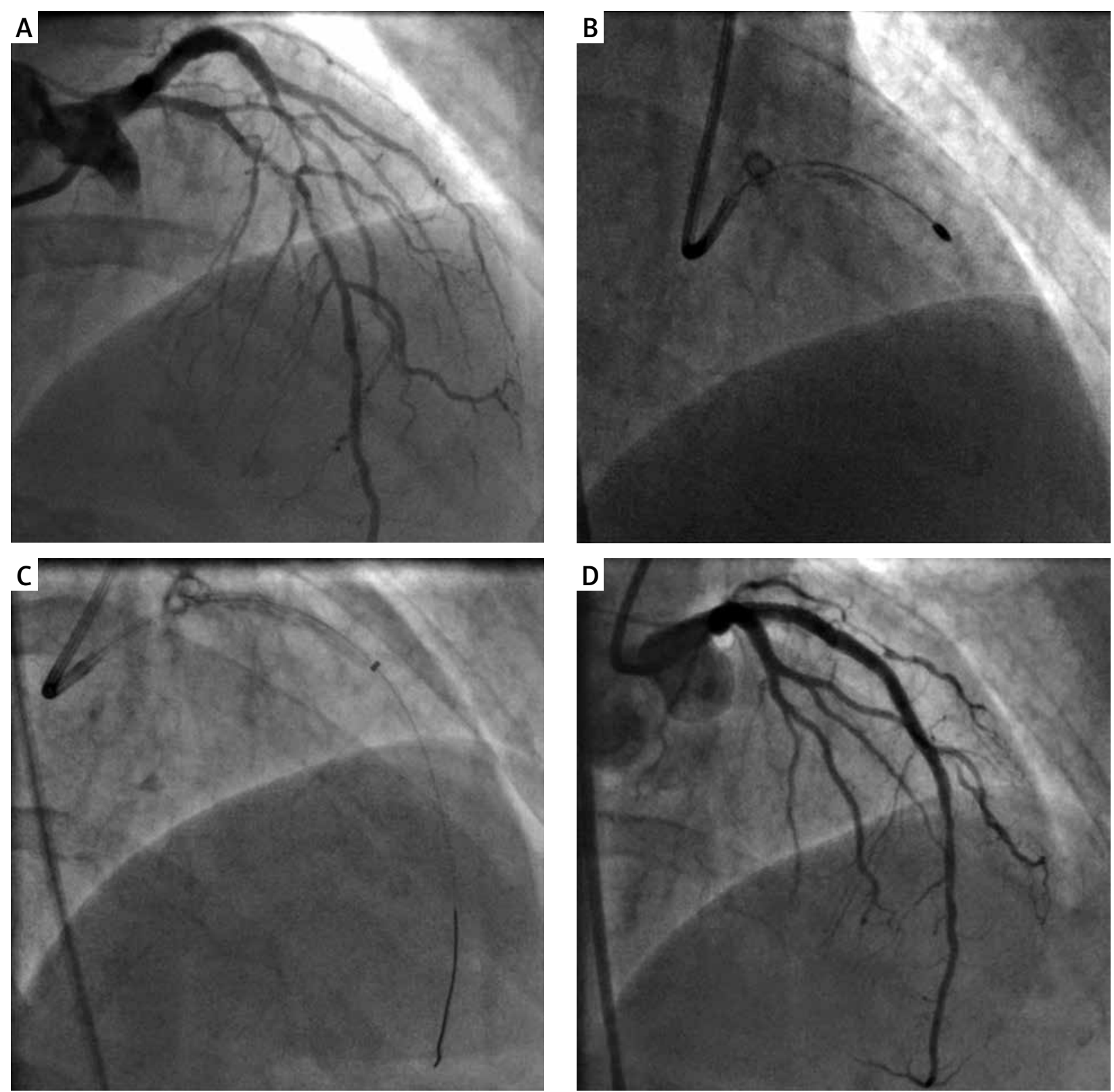

Figure 1. Critical, strongly calcified lesion in the left anterior descending before angioplasty (A), rotational atherectomy (B), stent delivery using GuideLiner catheter (C), final result of angioplasty (D)

\section{Conflict of interest}

The authors declare no conflict of interest.

\section{References}

1. Hachinohe D, Kashima Y, Kanno D, et al. Rotational atherectomy and new-generation drug-eluting stent implantation. Catheter Cardiovasc Interv 2018; 91: 1026-34.

2. Cuenza LR, Jayme AC, Khe Sui JH. Clinical outcomes of patients undergoing rotational atherectomy followed by drug-eluting stent implantation: a single-center real-world experience. Heart Views 2017; 18: 115-20.
3. Jinnouchi H, Kuramitsu S, Shinozaki T, et al. Five-year clinical outcomes after drug-eluting stent implantation following rotational atherectomy for heavily calcified lesions. Circ J 2018; 82: 983-91.

4. Januszek R, Siudak Z, Dziewierz A, et al. Predictors of in-hospital effectiveness and complications of rotational atherectomy (from the ORPKI Polish National Registry 2014-2016). Catheter Cardiovasc Interv 2017. doi:10.1002/ccd.27372. 